\title{
Growth of the bronchial tree in man
}

\author{
KEITH HORSFIELD, W IAN GORDON, WENDY KEMP, SALLY PHILLIPS
}

\author{
From the Cardiothoracic Institute, Midhurst, West Sussex
}

\begin{abstract}
Bronchial tree casts were made from one or both lungs from nine children aged from five weeks to 17 years. The branches of the casts were ordered by the method of Strahler, and diameter ratio, length ratio, and branching ratio were determined. From five to 12 weeks the diameter ratio is about $1 \cdot 35$, but by 13 months it has risen to $1 \cdot 45$, indicating a faster rate of growth in the larger airways over the period; thereafter it stays at or above this level. The data show that the peripheral conducting airways are relatively large in diameter at 1-3 months, attaining their adult proportion after one year. In contrast, length ratio shows no trend with age. On the assumption of 25000 terminal bronchioles, the mean number of orders between terminal bronchiole and trachea was estimated to be about 12 .
\end{abstract}

The mode of growth of the pulmonary airways has attracted an increasing amount of interest in recent years. The subject is important to paediatricians, physiologists, and pathologists, particularly with respect to understanding pulmonary disease and interpreting the results of lung function tests in children. Cudmore et al ${ }^{1}$ made bronchial tree casts of the upper lobes of 20 lungs and measured up to six axial pathways in each cast as far as the terminal bronchioles. They found that branch length increases in proportion to crown-rump length, and that the rate of growth decreases as distance from the carina increases. Boyden and Tompsett, ${ }^{2}$ studying the growth of dog lungs from serial sections, and using only those arising from the dorsal branch of the intermediate lobe, came to the opposite conclusionnamely, that growth is proportionately faster in the peripheral airways than in the central airways. Some of their peripheral branches, however, included respiratory bronchioles and these may have a different rate of growth from the conducting airways. Thurlbeck ${ }^{3}$ reviewed the data of Hieronymi, ${ }^{4}$ who studied generations of airways from $1 \mathrm{~mm}$ diameter down to respiratory bronchioles. He found that the more distal of these grow more quickly and that length increases faster than diameter after the age of one year. On the basis of measurements of postmortem bronchograms, Hogg et al ${ }^{5}$ reported that the peripheral airways of children under five years are relatively narrow and grow relatively slowly. This conclusion was thought by Hislop $e a^{6}{ }^{6}$ to be unjustified because the critical

Address for reprint requests: Dr KH Horsfield, Cardiothoracic Institute, Midhurst, West Sussex GU29 0BL.

Accepted 28 November 1986 part of the evidence appeared to be based on only one pathway. Their own data, ${ }^{6}$ which are based on measurements of one or three pathways in each of 12 lungs, show that both diameter and length increase in constant proportion during growth. Horsfield, ${ }^{7}$ using bronchial casts of dog lungs, came to the same conclusion.

In this paper the approach previously applied to dog lungs ${ }^{7}$ is used to study growth of human airways. It has the advantage that measurements are made of all Strahler ordered branches down to $0.5 \mathrm{~mm}$ diameter in the infant lungs and $1.0 \mathrm{~mm}$ in the bigger lungs, plus a sample of airways down to the terminal bronchioles.

\section{Methods}

Lungs were removed intact at necropsy from four infants aged 6-12 weeks, and from five children aged 13 months and seven, 13,15 , and 17 years (table 1 ). In two cases both lungs were available to us while in the others only one lung could be used.

Table 1 Age, sex, and cause of death of the subjects whose lungs were studied

\begin{tabular}{|c|c|c|c|}
\hline Age & Sex & Cause of death & Lung studied \\
\hline $\begin{array}{r}5 \mathrm{w} \\
6 \mathrm{w} \\
11 \mathrm{w} \\
12 \mathrm{w} \\
13 \mathrm{~m} \\
7 \mathrm{y} \\
13 \mathrm{y} \\
15 \mathrm{y} \\
17 \mathrm{y}\end{array}$ & $\begin{array}{l}\mathbf{F} \\
\mathbf{M} \\
\mathbf{F} \\
\mathbf{F} \\
\mathbf{M} \\
\mathbf{M} \\
\mathbf{M} \\
\mathbf{M} \\
\mathbf{M}\end{array}$ & $\begin{array}{l}\text { SIDS } \\
\text { SIDS } \\
\text { SIDS } \\
\text { SIDS } \\
\text { Bronchitis } \\
\text { Head injury } \\
\text { Subarachnoid haemorrhage } \\
\text { Head injury } \\
\text { Head injury }\end{array}$ & $\begin{array}{l}\mathbf{L} \\
\mathbf{L} \\
\mathbf{L} \\
\mathbf{R} \\
\mathbf{L} \\
\mathbf{R}+\mathbf{L} \\
\mathbf{R}+\mathbf{L} \\
\mathbf{R}+\mathbf{L} \\
\mathbf{L}\end{array}$ \\
\hline
\end{tabular}

SIDS — sudden infant death syndrome; $\mathrm{R}$-right; $\mathrm{L}$-left. 

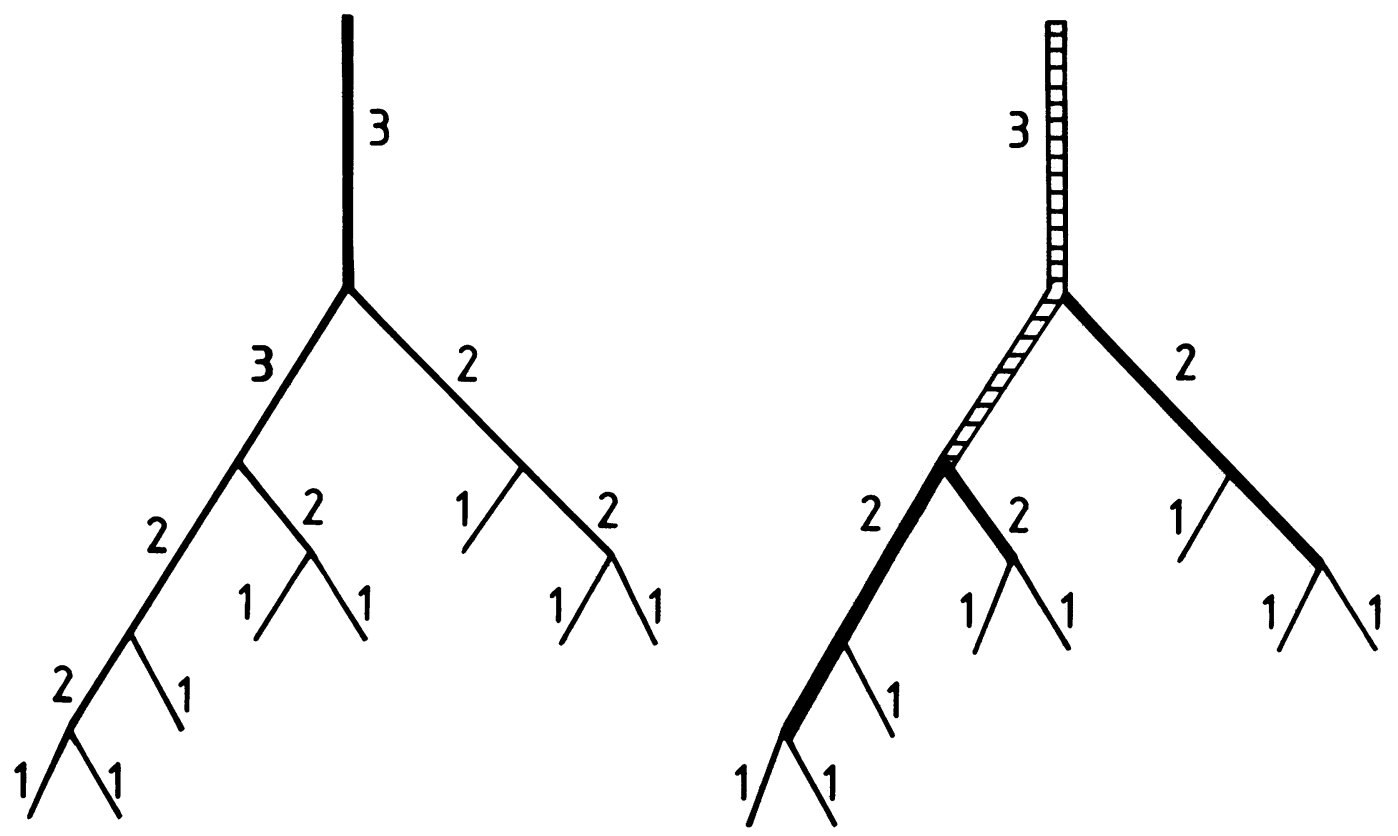

A

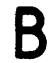

Fig 1 Strahler ordering: A-first stage; $B$-second stage (see, text).

Resin casts of the airways were made by the method of Tompsett. ${ }^{8}$ Briefly, the lungs were suspended and supported in a bath of normal saline at $34^{\circ} \mathrm{C}$, and inflated via the trachea with the same solution at a pressure of $25 \mathrm{~cm} \mathrm{H}_{2} \mathrm{O}$. A solution of gelatin $120 \mathrm{~g} / \mathrm{l}$ was run into the airways, the temperature being maintained to keep the gelatin liquid. The catalysed resin (AP 101, Trylon Ltd, Wellingborough, Northants) was next injected into the airways at a pressure of $30 \mathrm{~cm}$ of resin and allowed to set. The lungs were left to cool and next day were macerated in a solution of sodium hydroxide $120 \mathrm{~g} / \mathrm{l}$. Finally, the cast was washed clean and dried. The degree of filling of the cast is of some importance. If it is too full, the alveoli obscure the airways, which are then impossible to dissect out and measure. If it is insufficiently filled, too much information is lost. The correct degree of filling is achieved when peripheral airways are present with minimal casting of alveoli. This was achieved in all but one cast (age 12 weeks), on which the smaller airways were missing.

The order number of branches was determined by the method of Strahler. ${ }^{910}$ The merits of using orders (counting up) versus generations (counting down), and the different methods of ordering, have been discussed elsewhere. ${ }^{11-13}$ Briefly, Strahler ordering permits a better comparison between equivalent branches in an asymmetrical tree and, because of the linear plots of log mean diameter and log number of branches against order, it also facilitates comparison between trees. Peripheral branches are attributed order 1, and two of these meet to form an order $2 \vec{\partial}$ branch, order number increasing by one each time two equal order branches meet. When branches of $\underset{-}{x}$ differing order meet, the order of the higher branch is 3 . continued unchanged (fig 1A). Finally, contiguous branches of the same order are considered to constitute just one branch (fig 1B).

Because of the impractibility of measuring all the branches, the procedure was simplified by pruning the cast to some defined level, and taking samples of the cast peripheral to the level of pruning. This gives two or sets of data (the main cast and the samples), which are $N$ subsequently amalgamated. The level of pruning was N determined on a diameter criterion, which by experi- $\sigma$ ence we judged would leave about six orders of branching on the main cast. This cut off diameter was $0.5 \mathrm{~mm}$ in the lungs of children up to seven year old $\stackrel{\Phi}{\oplus}$ and $1.0 \mathrm{~mm}$ in the lungs of the three older children. Order 1 was then defined as the first branch up any pathway with a diameter equal to or greater than the $\mathbb{Q}$ cut off diameter. Peripheral samples were studied $\frac{P}{\mathbb{D}}$ under a dissecting microscope and a cut off diameter, $\cong$ from 0.1 to $0.5 \mathrm{~mm}$, was defined for each cast. Again, 
order 1 was defined as the first branch up any pathway with a diameter equal to or greater than the cut off diameter. The branching patterns were drawn, and Strahler orders determined on the drawing. Data from the samples in each case were then pooled.

Diameters and lengths of branches of the main cast were measured with a dial caliper graduated to $0.05 \mathrm{~mm}$ and read to the nearest $0.025 \mathrm{~mm}$. Dimensions of branches in the peripheral samples were measured under a dissecting microscope with an eyepiece graticule calibrated to $0.01 \mathrm{~mm}$ and read to the nearest $0.005 \mathrm{~mm}$. Diameters of Strahler ordered branches are measured in the middle of the highest segment, while lengths are the sum of all the contiguous branches of the same order.

When log number of brânches in each order is plotted against order number, linear plots are obtained. The branching ratio, $R b$, is defined as the antilog of the absolute value of the slope of the regression line; it is the factor by which the number of branches increases in successive orders down the tree. Similarly, when log mean diameter or length is plotted against order number linear plots are usually obtained. The antilog of the slope of the regression line is the diameter ratio $\mathbf{R d}$ or the length ratio, $\mathrm{Rl}$; it is the factor by which mean dimension increases in successive orders up the tree. In the case of lengths, however, data are more variable and the plots are less straight.

Broken branches were attributed an order by comparing their diameter with those of unbroken branches whose order had been determined. Compensation for the number of missing branches arising from broken branches was calculated as follows. The raw data for the number of branches in each order were used to calculate a provisional $\mathrm{Rb}$. The number thus obtained lay between 2.38 and 2.76 . If, for example, the provisional $\mathrm{Rb}$ was 2.5 and there were four broken branches in order 3 , then $2.5 \times 4=10$ missing branches would be assumed in order 2 . If in addition there were two broken branches in order 2 , then $(2+10) \times 2.5=30$ missing branches would be assumed in order 1 . When non-integer values were obtained they were rounded to the nearest integer. These missing branches were then added to the original data, $R \mathbf{b}$ was recalculated, and the above procedure was repeated. This algorithm was repeated until a stable value for $R b$ was obtained, which required from one to six iterations. The value of $\mathbf{R b}$ was calculated for the main cast and for the peripheral samples separately.

Plots of log mean diameter against order were used to determine the number of orders in the intact cast. This was done by plotting the data for the main cast and then finding by eye the best fit for the sample data so that they continued the line of the maincast data; an example of this is shown in figure 2. Having decided how to line up the diameter plots, the same line up of orders was used for the length plots. In all cases except the cast of the lungs from the 12 week infant, once the main cast data and peripheral sample data had been satisfactorily lined up, $R d$ and $R 1$ were calculated in the usual way from both data sets. For the 12 week lungs, for which there were no peripheral data, $\mathrm{Rd}$ and $\mathrm{Rl}$ were calculated from the main cast only.

An estimate of the number of orders from terminal bronchioles to right and left main bronchi was made where both lungs were available, or to the one main bronchus where only one lung was available. For both lungs the number of terminal bronchioles was taken to be $25000,{ }^{14}$ for the left lung $25000 \times 45 / 100$ $=11250$, and for the right lung $25000 \times 55 / 100=$ $13750 .{ }^{15}$ The number of terminal bronchioles $N \mathrm{tb}$ is given by

$$
N \mathrm{tb}=\mathrm{N} 1 \cdot \mathrm{Rb}(\mathrm{p})^{\mathrm{w}},
$$

where $N 1$ is the number of main cast order 1 branches calculated from the regression equation, $R b(p)$ is the peripheral $\mathrm{Rb}$, and $w$, the number of orders distal to main cast order 1 , is an exponent to be determined. From Eqn (1)

$$
\begin{gathered}
\log N \mathrm{tb}=\log N 1+w \cdot \log \mathrm{Rb}(\mathrm{p}) \\
w=(\log N \mathrm{tb}-\log N 1) / \log \mathrm{Rb}(\mathrm{p}),
\end{gathered}
$$

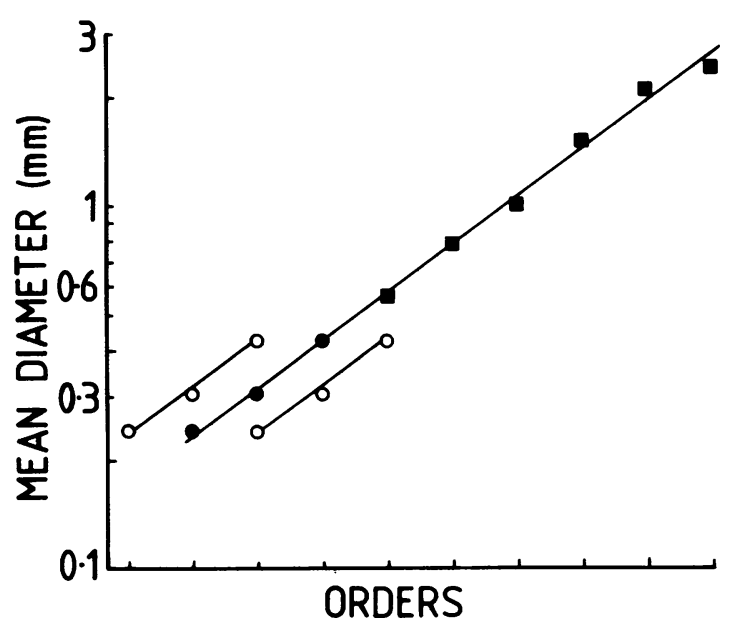

Fig 2 Lining up the diameter plots from the peripheral sample data with the main cast data. The squares are the mean diameters in each order of the main cast, and the regression line through them has been extended three orders to the left. The circles are the mean diameter in each order in the peripheral samples, and they have been plotted in three different positions. The closed circles clearly line up with the extended regression line. The open circles are one order out of alignment; the lines drawn through these are parallel to the regression line, and are put in to aid the eye. 
Table 2 Branching, diameter, and length ratios and calculated number of orders from terminal bronchiole to main bronchus in $\underset{\times}{\stackrel{D}{叉}}$ the lung casts

\begin{tabular}{|c|c|c|c|c|c|}
\hline Age & Main cast $R b$ & $\begin{array}{l}\text { Peripheral } \\
\text { sample } R b\end{array}$ & $R d$ & $R l$ & $\begin{array}{l}\text { Calculated } \\
\text { No of orders }\end{array}$ \\
\hline $\begin{array}{r}5 w \\
6 w \\
11 w \\
12 w \\
13 \mathrm{~m} \\
7 y \\
13 y \\
15 y \\
17 y \\
\text { Mean }\end{array}$ & $\begin{array}{l}2.84 \\
2.59 \\
2.55 \\
2.82 \\
2.40 \\
2.69 \\
2.67 \\
2.46 \\
2.81\end{array}$ & $\begin{array}{l}3.08 \\
2.23 \\
2.61 \\
2.61 \\
2.59 \\
2.21 \\
2.74 \\
2.54\end{array}$ & $\begin{array}{l}1.33 \\
1.38 \\
1.35 \\
1.35 \\
1.46 \\
1.47 \\
1.44 \\
1.54 \\
1.50\end{array}$ & $\begin{array}{l}1.68 \\
1.51 \\
1.52 \\
-1.67 \\
1.75 \\
1.65 \\
1.78 \\
1.55\end{array}$ & $\begin{array}{r}9.47 \\
11.77 \\
11.28 \\
10.01 \\
11.40 \\
10.75 \\
11.70 \\
11.37 \\
10.45 \\
10.91\end{array}$ \\
\hline
\end{tabular}

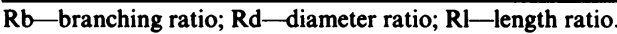

from which $w$ may be determined, and added to the number of orders in the main cast to give the total number of orders.

Statistical analysis was performed with nonparametric tests. Differences between values of $\mathbf{R d}$ and RI under and over one year of age were calculated with Wilcoxon's two sample rank test. Spearman's rank test was used to calculate the correlation coefficient Rs.

\section{Results}

Table 2 shows the values of $R b, R d$, and $R l$ obtained from the regression lines for the main cast and periph-

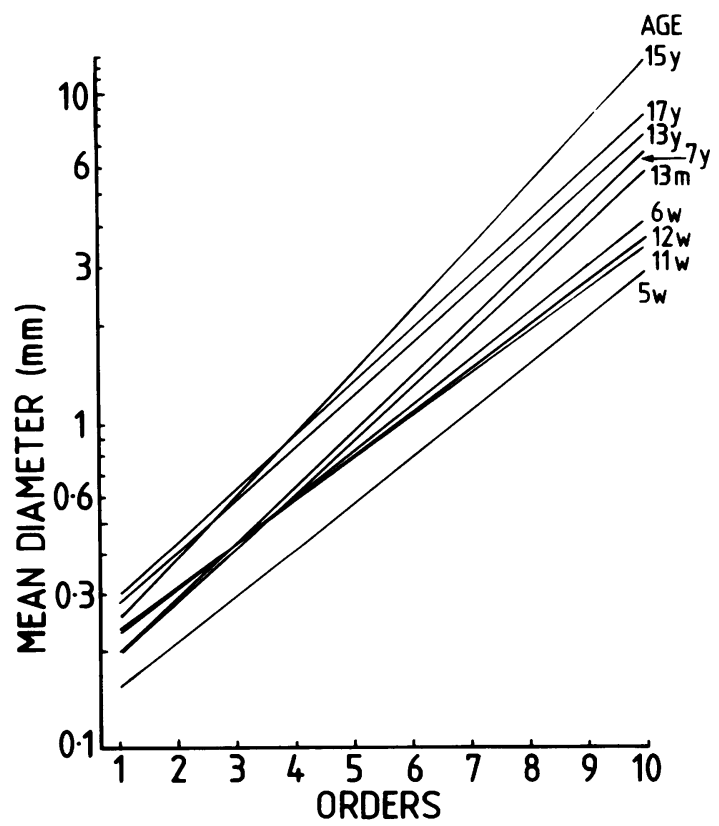

Fig 3 Regression lines from log diameter against order from nine airway casts. Order 10 represents the right and left main bronchi. The lines are steeper over the age of one year. eral samples in each lung, along with the calculated or numbers of orders from terminal bronchioles to the $\omega_{\infty}$ main bronchi. The value of $\mathrm{Rd}$ increases during the $\omega$ first year of life, being less than 1.4 below the age of 을 one year, and greater than 1.4 over one year $(p<-$ $0.05)$. Figure 3 shows the regression lines of $\log$ mean diameter against order for each lung; that for the six week old is higher than expected. The change in slope $\overrightarrow{0}$ of the regression lines after the age of one year may be $\stackrel{\infty}{-}$ readily appreciated, showing that the higher order airways grow more rapidly between three and 13 일 months. Values for diameter at order 10 correlate strongly with age $(\mathrm{Rs}=0.933, \mathrm{p}<0.01)$.

Figure 4 shows the corresponding plots of the

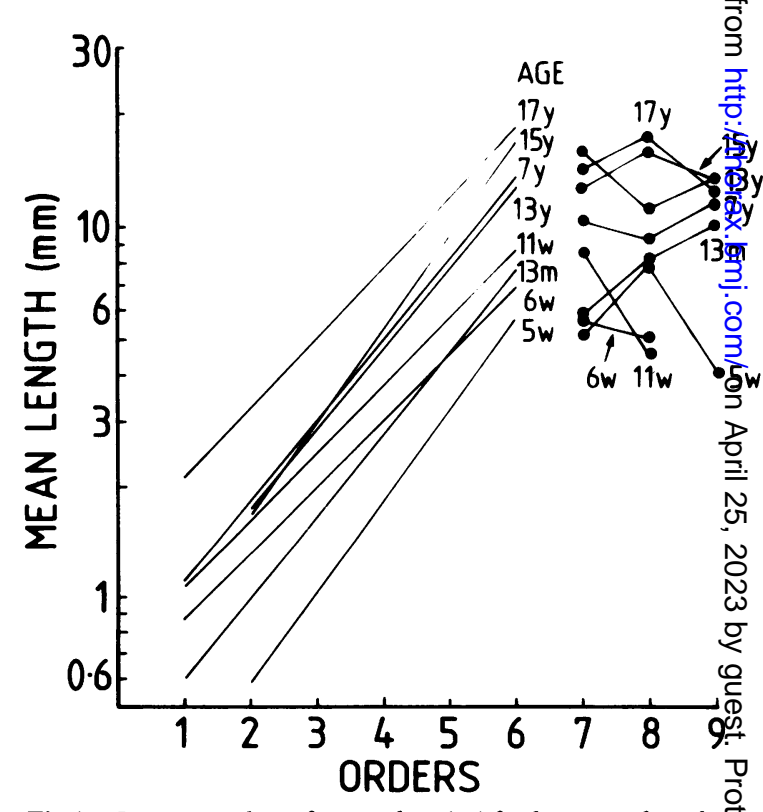

Fig 4 Regression lines from orders 1-6 for log mean length against order from eight airway casts (cast for 12 week old infant excluded). Also shown are the mean lengths of orders 7-9. 
regression of log mean length against order for orders up to 6 . That for the 13 month old is lower than expected. Linear plots are frequently not obtained with higher orders, ${ }^{7}$ so for these the mean data points have been plotted instead. Orders 10,9 , and 8 in figure 3 correspond to the two main bronchi, the lobar bronchi, and some of the segmental bronchi respectively. They occupy the region of the hilum and are shorter than expected because of space limitations in this region. In this study, however, order 7 is also shorter than expected, possibly because growth in length had not been completed. It should be pointed out that lengths of orders at the extremes of the range are not defined (because the exact points of termination are unknown) so that some of the length data encompasses only orders 2-9. In the three casts where data for order 1 was given, it had in fact proved possible to measure one order lower. Values for length of order 6 correlate strongly with age $(R s=0.952, p<$ $0.01)$. Rl under one year of age does not differ significantly from values over one year $(p>0.05)$.

The mean estimated number of orders was 10.91, range 9.47-11.77 (table 2); in round numbers, this gives 11 orders of branching from terminal bronchiole to main bronchus and 12 orders to the trachea.

\section{Discussion}

In the lungs from the younger children a "terminal bronchiole" in the present context refers to those airways that are destined finally to become terminal bronchioles. The point here is that retrograde alveolation of the airways continues for some time after birth, so that respiratory bronchioles become alveolar ducts and terminal bronchioles become respiratory bronchioles. ${ }^{3}$ Another important point is that, notwithstanding the process of alveolation, all the bronchi that eventually become conducting airways have been formed before birth. ${ }^{16}$ Although figures 3 and 4 show how, in general, diameter and length increase with age, nevertheless there are one or two regression lines that appear to be out of place. The most likely explanation for this is simply individual variation, although in the case of the six week old this could have arisen by an error of 1 in the attribution of orders. We have reconsidered the data with some care, but can find no evidence of an error in the order numbers.

It is interesting to compare our findings with those of other workers, with whom there is some agreement and some disagreement. Cudmore et $a^{1}$ also found that the rate of growth is less in the smaller airways, and with respect to diameter we concur with that view. Boyden and Tompsett ${ }^{2}$ reported that peripheral airways grow faster, but our findings do not agree with theirs, perhaps because the airways which they studied included respiratory bronchioles. Hieronymi ${ }^{4}$ found that in the small airways length increases more rapidly than diameter after the age of one year, and comparison of the left hand ends of the plots in figures 3 and 4 confirms this. Hogg et al ${ }^{5}$ claimed that the peripheral airways are relatively narrow in young children, but figure 3 shows that exactly the opposite is the case-that is, the peripheral conducting airways of infants are relatively greater in diameter. This is an important finding, because the young child's liability to bronchial infection has been partly attributed to narrowness of these airways. ${ }^{517}$ We would emphasise that our findings apply only to the conducting airways, as we have not attempted to measure intraacinar structures. Hislop et $a^{6}$ and Horsfield ${ }^{7}$ came to the conclusion that the conducting airways grow in constant proportion. The disagreement with the findings of Hislop et al remains unexplained, but may be a result of the different techniques used by the two groups. Horsfield's data, however, were obtained from dog's lungs, so the apparent discrepancy might be explained by a species difference in the mode of growth. We know of no other comparable data in animals with which our findings can be compared.

\section{References}

1 Cudmore RE, Emery JL, Mithal A. Postnatal growth of the bronchi and bronchioles. Arch Dis Child 1962;37:481-4.

2 Boyden EA, Tompsett DH. The postnatal growth of the lung in the dog. Acta Anat 1961;47:185-215.

3 Thrulbeck WM. Postnatal growth and development of the lung. Am Rev Respir Dis 1975;111:803-44.

4 Hieronymi G. Uber den durch das Alter bedingten Formwandel menschlicher Lungen. Ergeb Allg Pathol Anat 1961;41:1-62.

5 Hogg JC, Williams J, Richardson JB, Macklem PT, Thurlbeck WM. Age as a factor in the distribution of lower-airway conductance and in the pathologic anatomy of obstructive lung disease. $N$ Engl J Med 1970;282:1283-7.

6 Hislop A, Muir DCF, Jacobsen M, Simon G, Reid L. Postnatal growth and function of the pre-acinar airways. Thorax 1972;27:265-74.

7 Horsfield K. Postnatal growth of the dog's bronchial tree. Respir Physiol 1977;29:185-91.

8 Tompsett DH. Anatomical techniques. Edinburgh: Livingstone, 1970:123-9.

9 Strahler AN. Hypsometric (area-altitudes) analysis of erosional topography. Bull Geol Soc Am 1952;63: $1117-42$.

10 Strahler AN. Quantitative analysis of watershed geomorphology. Trans Am Geophys Union 1957;38: 913-20.

11 Horsfield K, Cumming G. Morphology of the bronchial tree in man. J Appl Physiol 1968;24:373-83. 
12 Singhal S, Henderson $\mathbf{R}$, Horsfield $\mathbf{K}$, Harding $\mathbf{K}$, Cumming G. Morphometry of the human pulmonary arterial tree. Circ Res 1973;33:190-7.

13 Horsfield K. The science of branching systems. In: Scadding JG, Cumming G, eds. Scientific foundations of respiratory medicine. London: Heinmann, 1981:45-54.

14 Horsfield K. The structure of the tracheobronchial tree. In: Scadding JG, Cumming G, eds. Scientific foundations of respiratory medicine. London: Heinmann,
1981:54-70.

15 Horsfield K, Dart G, Olsen DE, Filley GF, Cumming G. Models of the human bronchial tree. J Apply Physiol $\overrightarrow{\vec{S}}$ 1971;31:207-17.

16 Bucher U, Reid L. Development of the intrasegmental bronchial tree: the pattern of branching and devel- $\overline{\bar{c}}$ opment of cartilage at various stages of intra-uterine $\frac{\vec{\Phi}}{\Phi}$ life. Thorax 1961;16:207-18.

17 Engel S. The child's lung. London: Arnold, 1947. 